\title{
The Origin of Cortical Surround Receptive Fields Studied in the Barrel Cortex
}

\author{
Kevin Fox, Nicholas Wright, Helen Wallace, and Stanislaw Glazewski \\ School of Biosciences, Cardiff University, Cardiff CF10 3US, United Kingdom
}

The neocortex is thought to be organized into functional columns of neurons, each of which processes an element of a larger representation. In the barrel cortex, the thalamic input to the column preferentially terminates in a barrel. To study the extent and nature of functional connections between columns, we measured the degree to which whisker responses are relayed between columns in the barrel cortex. Inactivating a single barrel by iontophoresis of the $\mathrm{GABA}_{\mathrm{A}}$ agonist muscimol abolished the representation of that barrel's whisker in neighboring barrels. Reactivating a single barrel by iontophoresis of the $\mathrm{GABA}_{\mathrm{A}}$ antagonist bicuculline while the rest of the cortex was blocked by muscimol led to single whisker receptive fields. Under the same conditions, septal cells tended to exhibit multiwhisker receptive fields. These studies demonstrate that the surround receptive fields of barrel cells are generated by intracortical transmission and that many septal cells derive a component of their surround receptive field from the thalamus.

Key words: barrels; whiskers; GABA; rat; sensory processing; muscimol

\section{Introduction}

The cortical column is thought to be one of the basic elements of neocortical organization. A column is composed of a vertical array of cortical neurons that primarily processes one component of a larger representation (Mountcastle, 1957; Hubel and Wiesel, 1962; Szentagothai, 1975). The column is therefore primarily defined as a functional entity, but in the barrel cortex, the anatomical correlate of the column can also be seen in layer IV and is known as a barrel (Woolsey and Van der Loos, 1970). Thalamic axons project into layer IV, where they synapse mainly on the dendrites of stellate cells that orient their dendrites into the middle of the barrel (Simons and Woolsey, 1984). Vertically directed axons then project excitation from layer IV cells up into layers II and III of the column (Lubke et al., 2000), where neurons respond to whisker stimulation 2-3 msec after their layer IV counterparts (Armstrong-James et al., 1992). The neurons of individual barrel columns respond primarily to a single whisker on the whisker pad (Simons, 1985). However, neurons in a single barrel column respond to inputs from adjacent whiskers as well, measured in a variety of ways (Armstrong-James and Fox, 1987; Moore and Nelson, 1998; Zhu and Connors, 1999; Petersen and Diamond, 2000). Responses to the adjacent whisker inputs form

Received Feb. 20, 2003; revised June 10, 2003; accepted June 18, 2003.

This work was supported by grants from the Medical Research Council (United Kingdom) and the Human Frontiers Science Program Organization (K.F.). We thank Paul Chapman and Frank Sengpiel for critical reading of this manuscript and Danielle Green and Mervyn McKenna for undertaking the histology.

Correspondence should be addressed to Prof. Kevin Fox, School of Biosciences, Cardiff University, Museum Avenue, CardiffCF10 3US, UK. E-mail: foxkd@cf.ac.uk.

H. Wallace's present address: Institute of Child Health, Alder Hey Children's Hospital, Eaton Road, Liverpool L12 2AP, UK.

S. Glazewski's present address: McKay Institute of Communication and Neuroscience, Keele University, Staffordshire ST5 5BG, UK.

Copyright $\odot 2003$ Society for Neuroscience $\quad$ 0270-6474/03/238380-12\$15.00/0 the surround receptive fields of the cells. A key question for understanding how cortical processing occurs is to ask whether surround receptive fields arise from intracortical processing between neighboring cortical columns or whether, instead, they reflect convergence of information at subcortical sites.

The issue is important for a number of reasons. First, it concerns the way in which basic sensory processing occurs in the somatosensory cortex. Second, surround receptive fields exhibit substantial plasticity in mature somatosensory cortex, and it is necessary to know whether this is attributable to plasticity in cortical or subcortical pathways to discover the underlying plasticity mechanisms (Fox, 1994; Glazewski and Fox, 1996; Buonomano and Merzenich, 1998). Third, clues about cortical processing in a functionally relatively simple columnar structure like the somatosensory cortex could help uncover principles of cortical organization and thereby inform experimentation on cortical areas with more complex columnar processing (Fujita et al., 1992; Tsunoda et al., 2001).

Here we used a novel approach to examine the degree of intracortical processing that occurs in the barrel cortex. In the first series of experiments, we reversibly inactivated a single barrel by iontophoresis of muscimol ( $\mathrm{a} \mathrm{GABA}_{\mathrm{A}}$ agonist) to see whether this reversibly inactivated the corresponding whisker representation in surrounding cortical barrels. In the second series of experiments, we initially inactivated a large number of barrels simultaneously with muscimol diffused from the cortical surface to abolish activity in intracortical pathways. We then reactivated neurons in a single barrel with bicuculline (a competitive $\mathrm{GABA}_{\mathrm{A}}$ antagonist) to see whether surround receptive fields could be detected in the absence of intracortical activity. The results of both the muscimol and bicuculline iontophoresis studies imply that intercolumnar transmission forms a major feature of cortical receptive field processing, including that in layer IV. 


\section{Materials and Methods}

Subjects. Subjects were mature Long-Evans rats of 6-10 weeks of age. Twenty-three animals were used in the studies in which a single barrel was inactivated by muscimol iontophoresis. In addition, 24 animals were used in the studies in which the cortex was inhibited with muscimol and locally reactivated with bicuculline. In addition, nine animals were studied to characterize the effect of bicuculline on normal (untreated) cortex. Thalamic responses were studied during cortical muscimol application in an additional four animals.

Surgery, anesthesia, electrodes, and recording. The methods used were identical to those described in previous studies (Fox et al., 1996; Wallace et al., 2001), except that sodium pentobarbitone anesthesia $(65 \mathrm{mg} / \mathrm{kg})$ was used in some animals for comparison with urethane anesthesia (1.5 $\mathrm{gm} / \mathrm{kg}$ ). Briefly, a small craniotomy was made between 4 and $7 \mathrm{~mm}$ lateral to the midline and $1-4 \mathrm{~mm}$ caudal to bregma. Surgery relating to muscimol application is described below. Electrodes were single- or triple-barreled carbon fiber microelectrodes. Recordings were bandpassed between $600 \mathrm{~Hz}$ and $6 \mathrm{KHz}$, and spikes were discriminated using a voltage window discriminator.

Levels of anesthesia were monitored by recording focal EEG activity, spontaneous cortical spike activity, breathing rate, and reflexes. On the basis of these measures, we were able to categorize the anesthetic level according to the clinical stages of Guedal (1920) as demonstrated by Friedberg et al. (1999). Under pentobarbitone anesthesia, the anesthetic level was termed Guedal stage III-3 if a hindlimb pinch withdrawal reflex and corneal blink reflex were present and the respiratory rate was $60-86$ breaths/min. Anesthesia was termed stage III- 4 if both the hindlimb and corneal reflexes were absent and the respiratory rate was between 46 and 68 breaths/min. The anesthetic level was maintained at stage III-3 during administration of pentobarbitone and urethane anesthesia. Under urethane, this also corresponded to a state in which $\delta$ waves occurred at between 1 and $2 \mathrm{~Hz}$ with occasional spindle waves (Fox and ArmstrongJames, 1986). The breathing rate was slightly depressed under pentobarbitone ( $60-86$ breaths/min) compared with urethane anesthesia (100 120 breaths/min) at equivalent levels of anesthesia based on reflexes and focal EEG (stage III-3).

Sensory responses, stimulation, and quantification. The stimulus was a $200 \mu \mathrm{m}$ vertical deflection of a single vibrissa $\sim 10 \mathrm{~mm}$ from the face, delivered at $1 \mathrm{~Hz}$ (i.e., a $1^{\circ}$ deflection). The stimulator was a fast piezoelectric bimorph wafer attached to a lightweight glass capillary touching the vibrissa. Spikes were discriminated on the basis of amplitude and time course. All data were analyzed using poststimulus time histograms (PSTHs) and latency histograms. The response magnitude to stimulation of a particular vibrissa was defined as the number of spikes per stimulus occurring between 5 and $50 \mathrm{msec}$ after the stimulus minus the spontaneous activity occurring during an identical period before the stimulus. The modal latency was used to describe the response latency of the neuron. For a complete description, see the article by Armstrong-James and Fox (1987).

Histology. At the end of recording from each penetration, a small focal lesion (1.5 $\mu \mathrm{A}, \mathrm{DC}, 10 \mathrm{sec}$, tip-negative) was made at a site of known depth in layer IV. Electrodes were located at depths of between 550 and $750 \mu \mathrm{m}$. The cortex was flattened and processed for cytochrome oxidase histology as described before (Wong-Riley, 1979; Fox, 1994), and the location of each recording penetration was identified within the barrel field. In this way, we could identify the principal vibrissa for each recorded cell and, in the case of the dual-electrode recordings, the distance between the two electrodes.

Diffusion of muscimol. A small well was made above the cortex by first protecting the surface of the cortex with a small plug of Gelfoam and then covering the exposed area with agar. Once the agar had set, the Gelfoam plug was removed, leaving a small agar well above the cortex. The dura was retracted over several square millimeters, and muscimol dissolved in PBS was applied to the surface of the brain at known concentrations (100, 200 , and $500 \mu \mathrm{M}, \mathrm{pH} 7.4)$. The well of muscimol was replenished several times during the recording session to keep the concentration constant. The advance of muscimol into the cortex was measured by plotting PSTHs for the principal whisker response for cells at known depths. The depth was verified by making two lesions, one at the top and one at the bottom of the penetration at the end of the experiment and reconstructing the penetration from the histology.

It has already been shown that the time at which muscimol extinguished the principal whisker response as a function of depth can be described by diffusion from an interface of constant concentration (Wallace et al., 2001) as follows:

$$
C_{\mathrm{x}, \mathrm{t}}=C_{0} \operatorname{erfc}\left\{x /\left(D^{*} t\right)^{1 / 2}\right\},
$$

where $C_{\mathrm{x}, \mathrm{t}}$ is the concentration at a given depth and time; $C_{0}$ is the concentration at the surface; $\operatorname{erf} c$ is the error function complementary; $x$ is the depth within the cortex; $t$ is time; and $D^{*}$ is the modified diffusion coefficient for muscimol. The diffusion coefficient for muscimol was taken to be $\sim 8.7 \times 10^{-6} \mathrm{~cm}^{2} / \mathrm{sec}$ and was modified by values for tortuosity and volume fraction according to the following equation:

$$
D^{*}=\frac{\alpha D}{\lambda^{2}},
$$

where $\alpha$ is the volume fraction $(\sim 0.21)$, and $\lambda$ is tortuosity $(\sim 1.55)$ (Nicholson and Phillips, 1981). As muscimol reaches an effective concentration at $\sim 50 \mu \mathrm{M}$, we were able to block activity to a depth of $\sim 1 \mathrm{~mm}$ after $4 \mathrm{hr}$ with a surface concentration of $200 \mu \mathrm{M}$.

Iontophoresis of muscimol and bicuculline. Iontophoretic electrodes were either filled with muscimol or bicuculline metachloride (BMC, 10 $\mathrm{mm}, \mathrm{pH}$ 5.5; Tocris Cookson, Avonmouth, UK). A retaining current of 5-10 nA was usually applied depending on the electrode. The effective retain current was determined at the start of the experiment at a superficial location before moving the electrode to layer IV. Ejecting currents of $10 \mathrm{nA}$ were typically used in these studies for muscimol, although we often started with a higher current to offset the effect of previous retain charge, particularly if a retain current had been applied for a long period beforehand.

The period of current ejection was timed accurately. This precaution enabled us to keep the sphere of disinhibition localized to the tip of the electrode and to prevent epileptiform discharges. During ejection of muscimol, we generally maintained the ejecting current close to $10 \mathrm{nA}$ and monitored the evoked field potential for the principal whisker of the barrel concerned to judge when the barrel had been silenced.

The behavior of the muscimol diffusion with time was modeled by the diffusion equations solved for diffusion in an infinite medium from a point source (Carslaw and Jaeger, 1956) as follows:

$$
C_{(\mathrm{r}, \mathrm{t})}=\frac{Q}{4 \Pi D^{\star} r} \operatorname{erfc}\left\{r \alpha^{1 / 2} / 2\left(D^{\star} t\right)^{1 / 2}\right\}
$$

where $r$ is the radial distance from the point source; $Q$ is the flux of drug; and the other parameters have the same meanings as denoted above. The flux can be derived from the ejecting current as:

$$
Q=(i n) / F,
$$

where $i$ is the ejecting current; $F$ is the Faraday number; and $n$ is the transport number, which we have measured previously to average 0.242 with these electrodes (Armstrong-James et al., 1982).

The time at which principal whisker responses in neighboring barrels were first affected by muscimol diffusion gave a measure of how quickly muscimol diffused between the iontophoretic and recording electrodes. Using the same values as above for the modified diffusion coefficient for muscimol, it was found that the time at which cells were affected was predicted by the theoretical time course for diffusion. The concentration at which muscimol was effective was again found to be $\sim 50 \mu \mathrm{M}$ (see Fig. $2 A$ ). Because the behavior of muscimol followed simple diffusion laws, we were able to predict that $10 \mathrm{nA}$ would produce inhibition over no more than $300 \mu \mathrm{m}$ when applied for $33 \mathrm{~min}$ (see Fig. 1 B). Given that a barrel in the posterior medial subfield is at least $350 \mu \mathrm{m}$ in diameter in the rat, this allowed us to inhibit one barrel without affecting its neighbor when the electrodes were appropriately positioned. The best configuration occurred when the iontophoretic electrode was located on the far 
side of one barrel and the recording electrode was in the middle of the adjacent barrel. For $10 \mathrm{nA}$ ejecting current, the concentration reaches an asymptote of $\sim 50 \mu \mathrm{m}$ at $400 \mu \mathrm{m}$ (see Fig. $1 B$ ) as time tends to infinity. This makes it practically impossible for the neighboring barrel to be inhibited directly from the muscimol, whereas points within a $300 \mu \mathrm{m}$ radius are affected by the time $\sim 500 \mathrm{sec}$ have elapsed (i.e., $8.33 \mathrm{~min}$ ).

Definition of nomenclature for whiskers. The "principal whisker" is the topographically related whisker for the barrel in question; i.e., the D1 whisker is the principal whisker for cells in the D1 barrel. For septal cells, the closest barrel defined the principal whisker. The "surround whisker" refers to any whisker that forms part of the receptive field other than the principal whisker. The "secondary whisker" is one of the surround whiskers and is defined, for the first experiment, as the whisker related to the inactivated barrel; i.e., it is the D2 whisker if the muscimol iontophoresis electrode is located in the D2 barrel (see Fig. 1A). Typically in this study, we might record the D2 whisker responses in the D1 barrel while inactivating the $\mathrm{D} 2$ barrel with muscimol.

For the second experiment, in which the cortex was inactivated by muscimol and locally reactivated with BMC, secondary, tertiary, and so forth $\left(2^{\prime}, 3^{\prime}\right.$, and so forth) mean the whiskers giving the second, third, and so forth largest responses.

Analysis. Sensory responses were quantified by calculating the average response level across cells subject to the same treatment. To judge the effect of muscimol iontophoresis in the neighboring barrel on the surround receptive field, we compared a period of control responses (usually 20-30 $\mathrm{min}$ ) with the response after the neighboring barrel was inactivated. The principal and secondary whisker responses from this period were averaged across cells and compared with average control values for the same cells.

To quantify the size and focus of receptive fields, surround receptive field responses were categorized according to how large a response they generated in each cell. Average response levels were then calculated for the principal whisker and corresponding secondary, tertiary, and so forth surround whiskers. To judge the effect of the various treatments on the composition of the surround receptive fields, average surround receptive field responses were normalized to the average principal whisker response for particular cases and compared between control and muscimol-treated cases using a $t$ test.

\section{Results \\ Cortical receptive fields in the absence of activity in a single barrel}

To inactivate a single barrel, muscimol was iontophoresed in layer IV. A second electrode was inserted into an adjacent barrel to record the receptive field properties in layer IV during inactivation of the neighboring barrel (Fig. 1A). We had previously found that cells lose their sensory responses at a muscimol concentration of $\sim 50 \mu \mathrm{M}$ in barrel cortex (Wallace et al., 2001). Iontophoresis using $10 \mathrm{nA}$ ejecting current would be expected to raise the muscimol concentration to $50 \mu \mathrm{M}$ at $300 \mu \mathrm{m}$ from the tip of the electrode within $\sim 7 \mathrm{~min}(420 \mathrm{sec})$, whereas at $400 \mu \mathrm{m}$, it would take at least $33 \mathrm{~min}(2000 \mathrm{sec})$ to raise the concentration to the same level (Fig. $1 B$ ). Therefore, we attempted to place the electrodes at $>300 \mu \mathrm{m}$ separation in the horizontal plane to give sufficient time between inactivating one barrel and its neighbor to accurately record the effect on the receptive field.

In practice, the electrodes were found to have been located at a variety of separations when the histology was examined (see Materials and Methods). The point at which cells located at the recording electrode were affected directly by iontophoresis of muscimol was estimated by measuring the time taken to cause a significant decrease in the principal whisker response (for nomenclature, see Materials and Methods). The farther the cell was located from the iontophoretic source, the longer it took for the principal whisker response to be affected. The experimental time points for first affecting the principal whisker response all lay
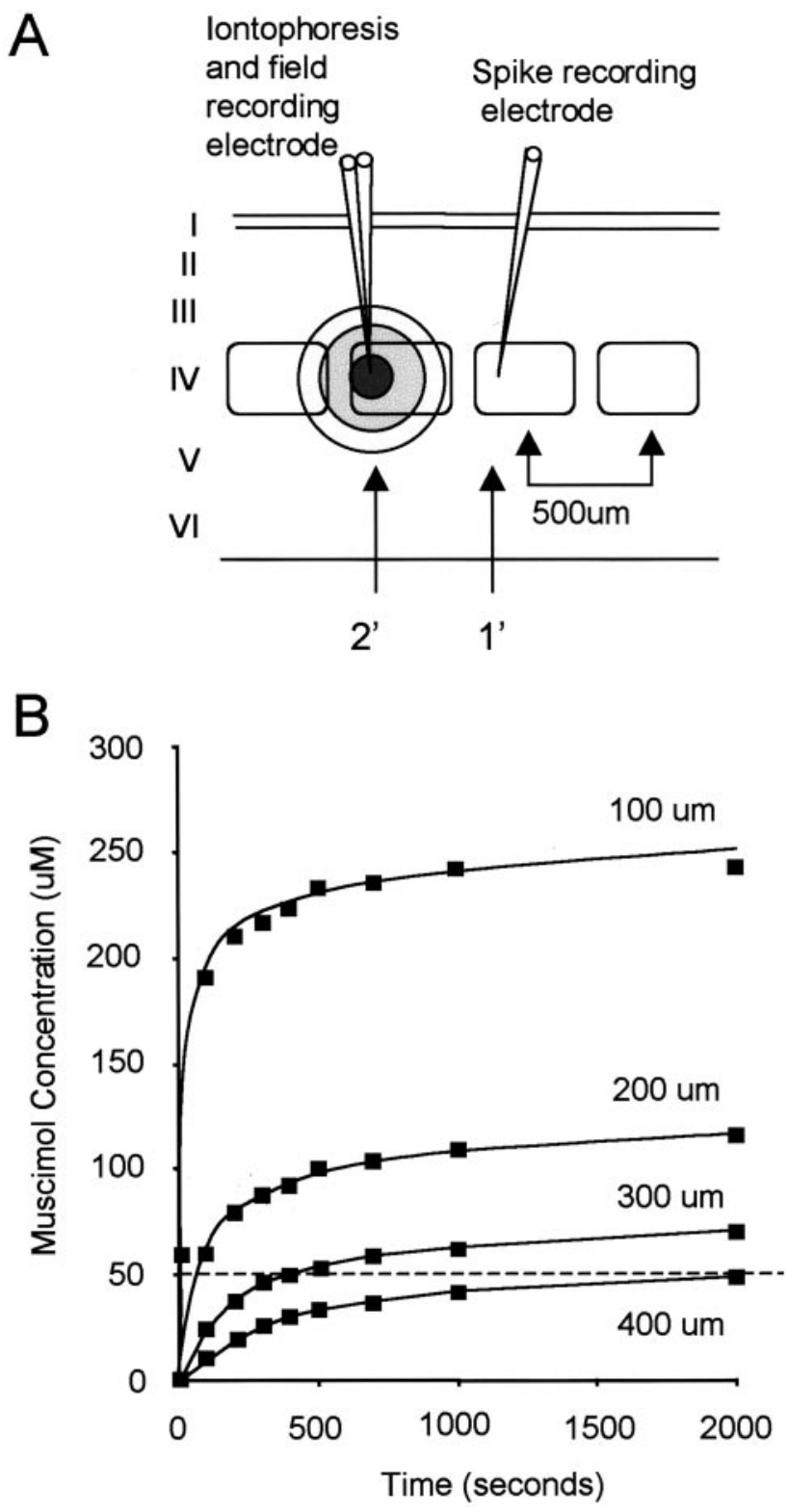

Figure 1. Inactivation of a single barrel by muscimol iontophoresis. $A$, Two electrodes were located in adjacent barrels. The three-barrelled (only 2 shown in the diagram) iontophoresis electrode, shown on the left, monitored activation of the barrel in which it was located by field potentials evoked from the principal whisker. Muscimol was delivered via one of the iontophoretic barrels, usually at a current of $10 \mathrm{nA}$. The second electrode was located in the adjacent barrel and measured responses to the principal whisker for its barrel ( $1{ }^{\prime}$ whisker) and the response to the whisker related to the barrel with the iontophoretic electrode in it (secondary whisker, $\left.2^{\prime}\right)$. The arrows indicate the barrels corresponding to the principal $\left(1^{\prime}\right)$ and secondary $\left(2^{\prime}\right)$ whiskers. Ideally, the iontophoretic electrode was located on the far side of the barrel from the second recording electrode as shown. $B$, The time course of concentration achieved by muscimol iontophoresis at different distances from the electrode can be estimated from the diffusion equations (see Materials and Methods), shown here for constant flux at $10 \mathrm{nA}$. The dashed line indicates a concentration of $50 \mu \mathrm{m}$. Knowing that muscimol inactivates cells at $\sim 50 \mu \mathrm{m}$ in the barrel cortex (Wallace et al., 2001), it can be seen that it takes points at a radius of 400 $\mu \mathrm{m}$ four times as long to reach $50 \mu \mathrm{m}$ as points at $300 \mu \mathrm{m}$. Given that the distance between the centers of the large barrels are $\sim 500 \mu \mathrm{m}$ apart, this allows a single barrel to be inactivated without affecting its neighbor given the configuration shown in $A$ ( $1500 \mathrm{sec}=25 \mathrm{~min})$.

close to the theoretical line for the time at which muscimol reached $50 \mu \mathrm{M}$ by diffusion from the iontophoresis electrode (Fig. 2A, dashed line). Furthermore, the best straight line fit through the data points (solid line; $R^{2}=0.78$ ) almost superim- 
A

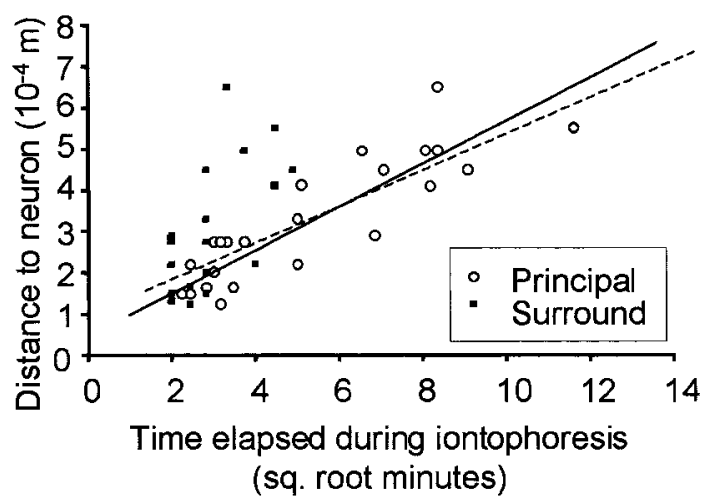

B

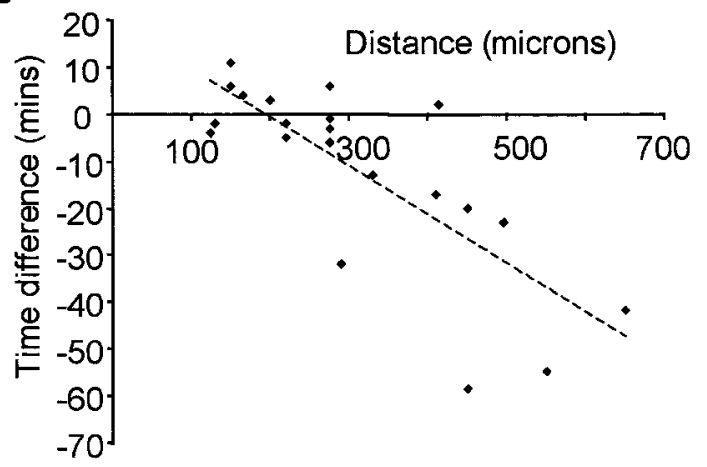

Figure 2. Time course of muscimol diffusion and barrel inactivation. $A$, The time represented on the $x$-axis is the time that elapses after switching on the ejecting current at the iontophoretic electrode. Points are plotted at the time when the response to either the principal or secondary whisker response can first be detected to decrease after beginning to eject muscimol. The time taken for muscimol to affect the principal whisker response for the first time (white circles) is plotted against the distance between the cell and the iontophoresis electrode. The best straight line fit through these points is shown by the solid line $\left(R^{2}=0.78\right)$, which corresponds well with the theoretical plot of the isoconcentration contour for muscimol diffusing from a point source to reach a concentration of $50 \mu \mathrm{m}$ (dashed line). A reduction in the principal whisker response can therefore be accounted for by muscimol diffusing from the iontophoretic electrode to the location of the cell and inhibiting it directly. A delay of 2 min is added to the theoretical curve to take account of the delay between turning on the current and the drug first appearing at the electrode tip. The time at which the secondary whisker response (black squares) is first affected is also plotted against the distance from the cell to the iontophoresis electrode. The black points nearly all lie some distance from the $50 \mu \mathrm{m}$ isoconcentration contour, and the points are fitted poorly by a straight line $\left(R^{2}=0.45\right.$; line not shown), indicating that the secondary whisker response cannot be explained by direct diffusion of muscimol to the site of the cell. However, the effect is far clearer for electrode separations of $>300 \mu \mathrm{m}$. B, The delay between the time at which we could first detect a decrease in the principal whisker response and the time at which the surround whisker response was completely abolished is plotted against the distance between the cell in question and the iontophoresis electrode. Negativetime differences indicate that the secondary whisker response is abolished before the principal whisker response is even slightly decreased. If decreases in both princi$\mathrm{pal}$ and secondary whisker responses were attributable to diffusion of muscimol to the site of the recorded cell, the time difference would be constant at approximately zero and independent of the distance between the cell and the iontophoretic electrode. In fact, time differences increase with electrode separation (note the negative slope of the best fit dashed line), indicating that both effects cannot be explained by muscimol diffusion to the site of the recording electrode. Useful delays occur for separations of $>300 \mu \mathrm{m}$, as would be predicted from theory (see Fig. 1B).

poses on the theoretical line representing the $50 \mu \mathrm{M}$ isoconcentration contour. This both confirms that the muscimol behaved approximately as predicted by diffusion from a point source (see Materials and Methods) and that the effect on the principal whis- ker response could be explained by diffusion of the muscimol to the site of the recorded cell.

In contrast, responses were lost far more rapidly for the whisker related to the inactivated barrel (which we define here as the secondary whisker). The time at which the first sign of a reduction in the secondary whisker response occurred (Fig. $2 \mathrm{~A}$, black squares) was far earlier than that for the principal whisker response and too early to be explained by direct diffusion of muscimol except in cases in which the iontophoretic electrode was located very close to the recorded cell. Consequently, the difference in time between affecting principal and secondary whisker responses was similar for cells located close to the iontophoretic electrode and very different for cells located farther away (Fig. $2 B)$. Furthermore, the best straight line fit fitted the data poorly $\left(R^{2}=0.45\right.$; Fig. $2 A$; note that the data points are shown but not the linear fit). This indicates that affecting the secondary whisker response depended on inhibiting something closer to the iontophoretic electrode than the recorded cell when the iontophoretic electrode was distant from the recorded cell.

Useful distances between the recorded cell and the iontophoretic electrode occurred for separations of at least $300 \mu \mathrm{m}$. It took at least $10 \mathrm{~min}$ to first affect the principal whisker response after abolishing the secondary whisker response for seven of eight cells where the electrodes were located $>300 \mu \mathrm{m}$ apart (Fig. 2 B). Note that negative times indicate that the secondary whisker response was lost before the principal whisker response was affected at all. Figure 3 shows two examples of recordings in which the response to the secondary whisker was abolished for a long period with a minimal effect on the principal whisker response. In all cases, cells showed recovery of the surround whisker response when the iontophoretic current was switched to retain.

The average response to the secondary whisker decreased to $5 \%$ of control values during inactivation of the adjacent barrel [control response, $35.8 \pm 5.4$ spikes per 50 stimuli (sp/50 st); test response, $1.9 \pm 1.2 \mathrm{sp} / 50 \mathrm{st} ; n=7)$, a reduction that was statistically significant ( $p<0.01 ; t=9.9$; $\mathrm{df}=6)$. During the same period, the principal whisker response fell to $88 \%$ of control values (control response, $98.3 \pm 18.2 \mathrm{sp} / 50 \mathrm{st}$; test response, $86.4 \pm$ $10.6 \mathrm{sp} / 50 \mathrm{st})$, which was not significantly different from control $(p>0.05 ; t=0.98 ; \mathrm{df}=6$; Fig. 4$)$.

Cortical receptive fields in the absence of intracortical activity To inactivate synaptic transmission between barrel columns, we applied muscimol to the surface of the cortex and allowed it to diffuse throughout the depth of the cortex (Fig. 5A). Within $\sim 4$ hr of the first application of muscimol $(200 \mu \mathrm{M})$, all sensory responses were abolished to a depth below layer $\mathrm{V}$. Low-voltage activity $(30 \mu \mathrm{V})$ remained in layer IV after blocking postsynaptic responses and was considered to originate from presynaptic thalamic fibers because it did not respond to iontophoresis of glutamate (Wallace et al., 2001). Putative thalamocortical fiber activity was recorded on 12 occasions and was always found to respond within 5-8 msec of whisker stimulation. The postsynaptic responses to the principal whisker at the same location could be measured before the block had occurred or by iontophoresis of bicuculline after the muscimol had blocked responses. In all cases, postsynaptic responses were found to be $1-3 \mathrm{msec}$ later than that of the low-voltage activity.

Sensory responses were recorded before blocking intracortical transmission to compare them with responses after drug treatment. Sensory responses were recorded during blockade of intracortical transmission by low-level iontophoresis of BMC. The $\mathrm{IC}_{50}$ for displacement of muscimol from $\mathrm{GABA}_{\mathrm{A}}$ receptors by 


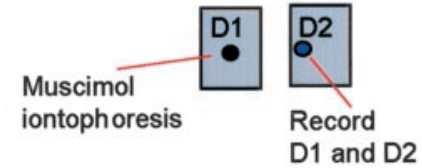

D2
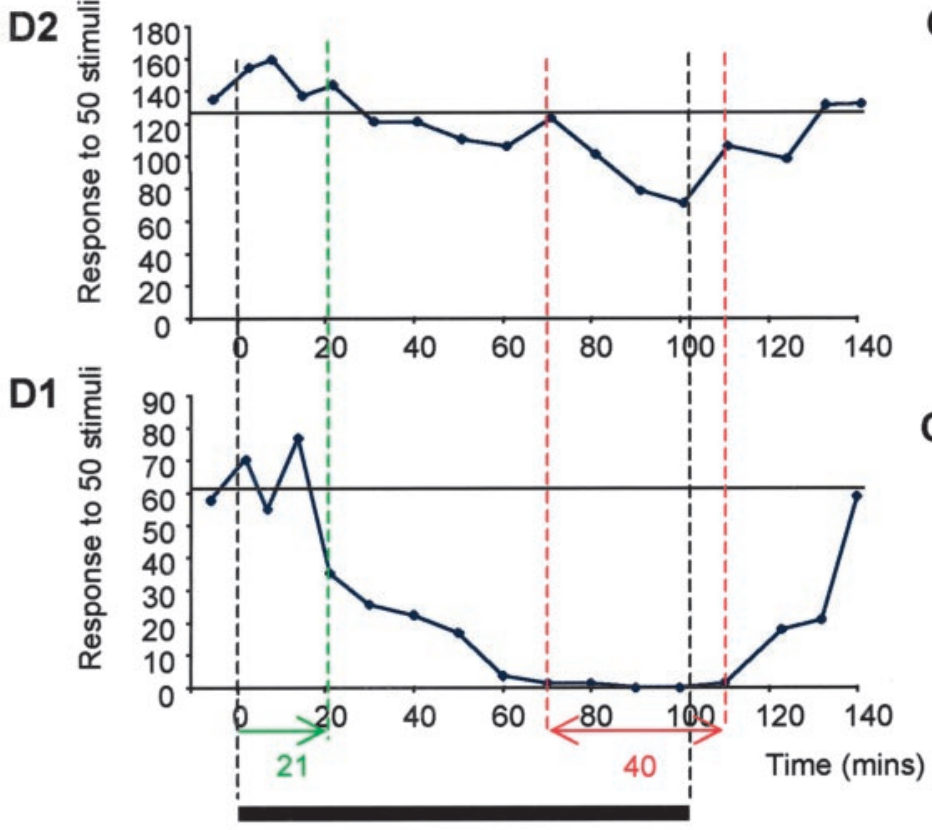

Muscimol iontophoresis (5-15nA)

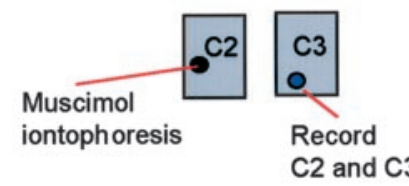

C3

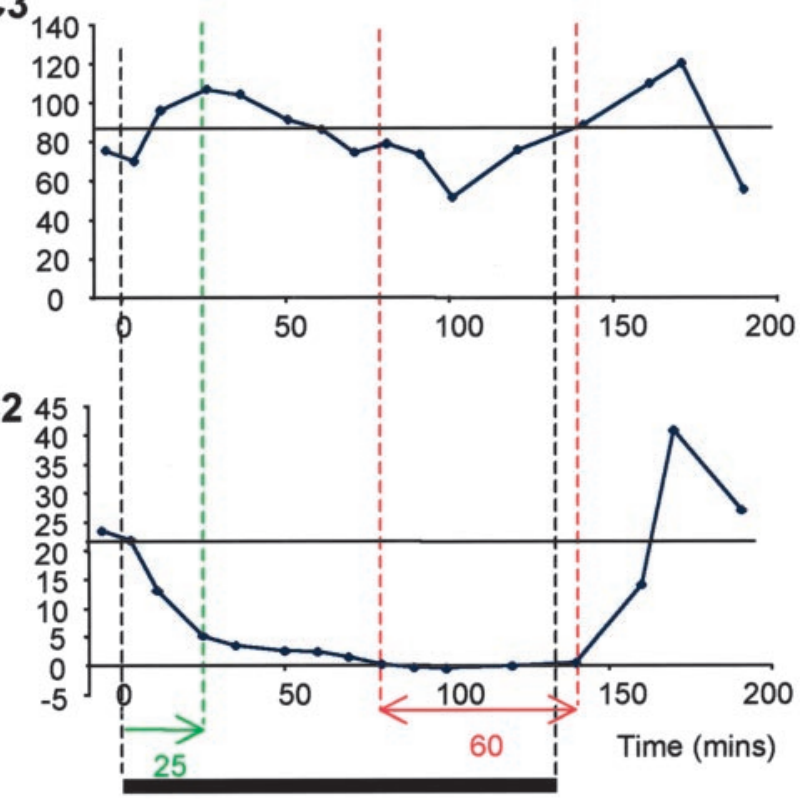

Muscimol iontophoresis (10nA)

Figure 3. Examples of responses to principal and surround whiskers during barrel inactivation. $A$, The iontophoresis electrode is located in the D1 barrel, and the recording electrode is located in the D2 barrel. Responses to the D1 and D2 whisker recorded in the D2 barrel are shown. Approximately 21 min after turning on the iontophoretic current, the surround whisker response (to D1) is first affected (green dashed line). The iontophoretic current was adjusted down from 15 to $5 \mathrm{nA}$ during the next 40 min as the surround response is gradually abolished. The surround whisker response is lost at $70 \mathrm{~min}$ (left-most red line), but the principal whisker response is unaffected at this point. During the following $40 \mathrm{~min}$, the principal whisker response starts to be affected by the muscimol because it is located on the near side of the barrel to the iontophoresis electrode. On switching the current to retain, the surround whisker response recovers within 40 min. $B$, When the electrodes are located farther apart than the example shown in $A$, the principal whisker response (C3) is not significantly affected during prolonged abolition of the surround whisker response ( $C 2$ in this case) for $60 \mathrm{~min}$. Responses to stimulation of the C 3 and ( 2 whisker are shown for a cell located in the C 3 barrel. The C 2 whisker response recovers on application of retaining current to the iontophoretic electrode located in the $\mathrm{C} 2$ barrel. Black bars indicate the period during which ejecting current was applied to the iontophoretic electrode. The dashed green line shows the time at which the surround whisker response was fist affected, and the dashed red line shows the period when the surround whisker response was abolished. The horizontal line shows the average control response level for each whisker.

bicuculline is $\sim 20 \mu \mathrm{M}$ (Huang and Johnston, 1990). This implies that to maintain very local diffusion when ejecting BMC, we require less than half the iontophoretic current needed to eject muscimol ( $<5 \mathrm{nA}$; Fig. 5B). This corresponded to using currents of 1-5 nA for $<10 \mathrm{~min}$. In four cases, sensory responses were recorded after the effect of muscimol had worn off. Most of the cells were located within the boundaries of the barrel itself, but some were found in septal locations (Table 1).

\section{Neurons located within barrels}

In normal untreated cortex, most barrel neurons exhibited a surround receptive field (71\%), whereas $29 \%$ only responded to the principal whisker. Most surround receptive fields comprised one other whisker ( $47 \%$ of all cells recorded) but could exhibit receptive fields of up to five whiskers. After inactivating intracortical activity with muscimol and reinstating local activity with bicuculline, almost none of the neurons exhibited a surround receptive field $(3.6 \%)$, but they showed a powerful response to the principal whisker. The decrease in the proportion of cells exhibiting a surround receptive field in the absence of intracortical activity was statistically significant $\left(p<0.01 ; \chi^{2}=14 ; \mathrm{df}=1\right)$.
Figure 6a shows an example of a cell that responded to five whiskers before blocking cortical activity (only three whisker responses are shown here for clarity). Applying muscimol blocked all responses, but after local disinhibition with BMC, only the principal whisker response was reinstated. On average, the surround receptive field whisker that gave the greatest response was found to evoke $\sim 42 \%$ of the principal whisker response in untreated animals. However, after applying muscimol to the cortex and locally disinhibiting with bicuculline, the surround receptive field whisker generating the greatest response was just $2.2 \%$ of the principal whisker response, which was significantly different from control ( $p \ll 0.01$; df $=42)$.

The average response of the principal whisker could be increased greatly above control levels without revealing a surround receptive field component (Fig. 7). On average, the principal whisker response reactivated by $\mathrm{BMC}$ was $213 \%$ greater than the average control principal whisker response (test, $163.04 \mathrm{sp} / 50 \mathrm{st}$; control, $76.64 \mathrm{sp} / 50 \mathrm{st}$ ). In contrast, in the few cases in which any surround whisker response was detected, the $2^{\prime}$ whisker response intensity was just $13 \%$ of the control level (test, $4.44 \mathrm{sp} / 50 \mathrm{st}$; control, $34.29 \mathrm{sp} / 50 \mathrm{st} ; t=6.99 ; p \ll 0.01$; df $=42)$. The $3^{\prime}-5^{\prime}$ 


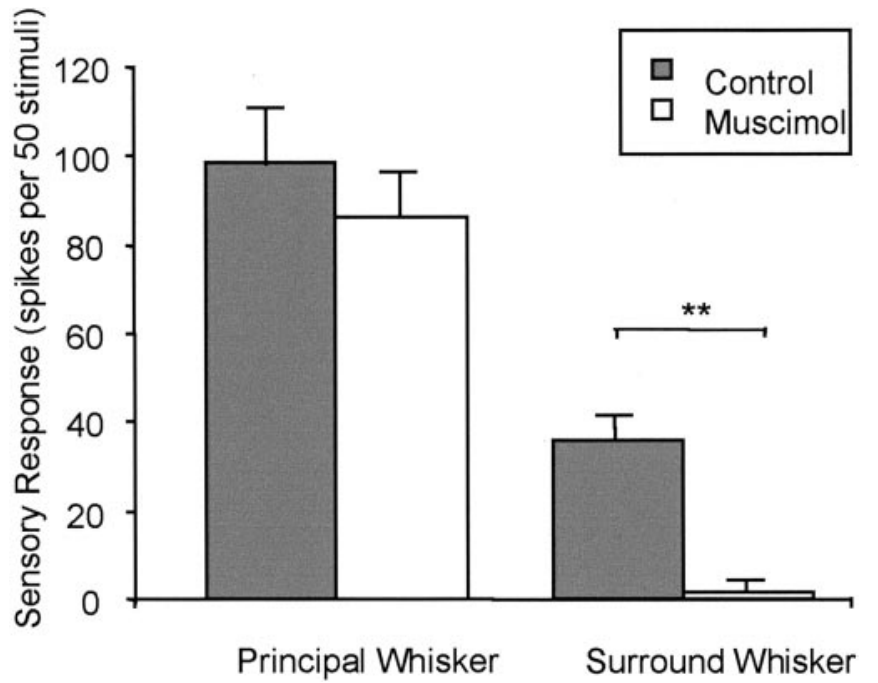

Figure 4. Quantification of the principal and secondary whisker responses before and after muscimol application to the adjacent barrel. The average responses of eight cells recorded for electrode separations of $>300 \mu \mathrm{m}$ are shown. Responses before inhibiting the neighboring barrel (gray bars) are compared with responses during inhibition (white bars). Responses are expressed as the number of spikes produced in response to 50 stimuli. Although the principal whisker responses are not significantly affected, the secondary whisker responses are practically abolished by inactivation of the neighboring barrel. ${ }^{*}$ Significant differences at $p<0.01$.

components of the receptive field were completely abolished in muscimol-treated cortex despite the local reactivation with BMC and were therefore also highly significantly different from control receptive field responses (Fig. 8).

To compare the effect of local disinhibition in the absence of transbarrel communication with local disinhibition in the presence of transbarrel communication, we also applied BMC in otherwise untreated cortex. BMC was iontophoresed at the same current $(1-5 \mathrm{nA})$ for the same time limit $(<10 \mathrm{~min})$ as it had been in muscimol-blocked cortex. We found that BMC increased the principal whisker response to $201 \%$ of control levels (average value for 38 cells), which was very similar to its effect in muscimol-blocked cortex (213\% of control). However, BMC also had a profound effect on the surround receptive field components in unblocked cortex, unlike its action in muscimoltreated cortex, where it had little or no effect (Fig. 7). All whiskers contributing to the surround receptive field increased in the presence of BMC (Fig. 7C), whereas they were absent in the presence of BMC in muscimol-treated cortex (Fig. $7 B$ ). The secondary whisker responses increased to $317 \%$ of control in unblocked cortex versus $13 \%$ in blocked cortex, and this difference was significant $(t=8.56 ; p \ll 0.01 ; \mathrm{df}=37)$. Similar observations were made for the other surround receptive field whiskers ( $3^{\prime}$ whisker, 297 vs $0 \%$; $4^{\prime}$ whisker, 281 vs $0 \%$; and $5^{\prime}$ whisker, 222 vs $0 \%$; $p \ll$ $0.01 ; \mathrm{df}=37$ for all cases; Fig. $7 B, C$, compare gray bars).

\section{Neurons located in septa}

The effect of blocking intracortical transmission was less pronounced for septal cells. As shown in Figure $6 B$, some cells retained a minor response from a surround receptive field whisker when treated locally with BMC while the surrounding cortex was blocked with muscimol. Although $42 \%$ of the septal cells lost all surround receptive field responses during blockade of intracortical transmission, just like the barrel cells, the rest retained input from at least one other whisker (68\%; Fig. 8). The number of cells recorded in septal regions in muscimol-treated cortex was rela-
A

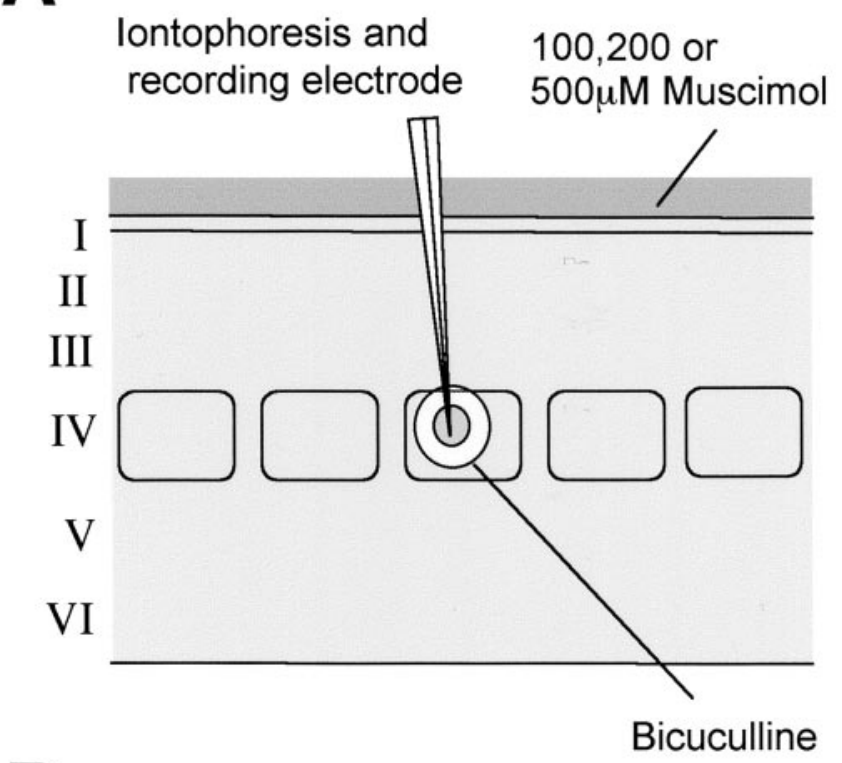

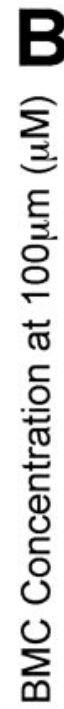

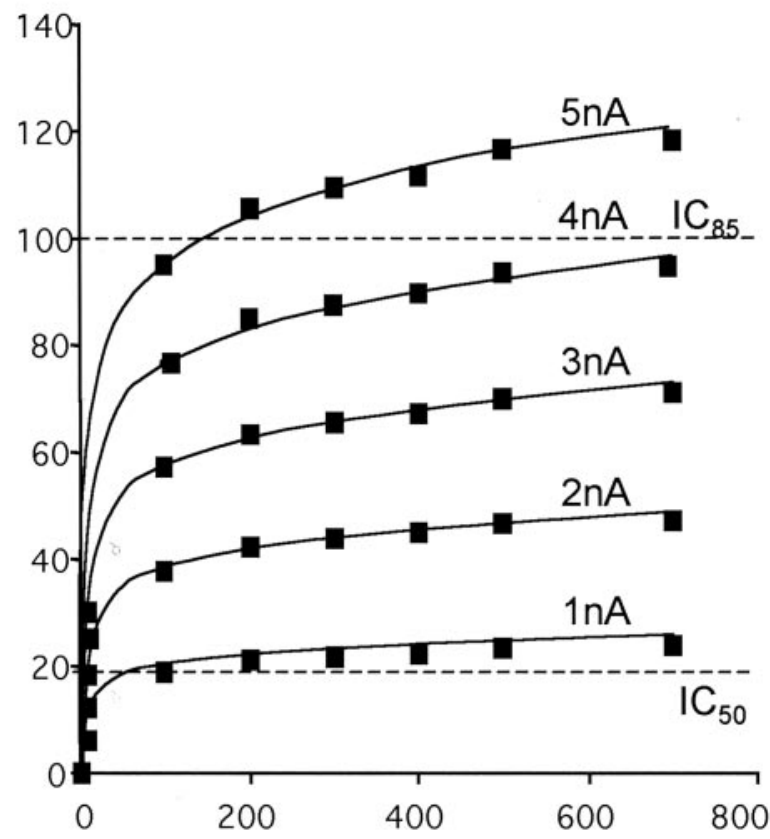

Time (seconds)

Figure 5. Reactivation of a single barrel. $A$, Muscimol is applied to the surface of the cortex to inactivate intracortical transmission over a number of cortical columns. After several hours of diffusion, the muscimol reaches layer VI in effective concentrations. An electrode recording sensory responses monitors the advance of the muscimol inhibition. When the block is complete, cells are locally reactivated by low-level iontophoresis of bicuculline from an iontophoretic electrode. Note that two barrels contained bicuculline, but only one ejected bicuculline at any one time, the other providing a backup facility. The sphere of reactivation is maintained below the radius of the barrel by using low iontophoretic currents $(1-5 \mathrm{nA}) . B$, The time course of bicuculline ejection is plotted for various ejecting currents between 1 and $5 \mathrm{nA}$ at a distance of $100 \mu \mathrm{m}$ from the tip of the electrode. Note that the concentration stabilizes relatively quickly after the first 20 sec at these low currents. In practice, a 1 or 2 min delay occurred before the drug appeared because of the effect of the retain current (see Fig. 2A). The dashed lines show the approximate $\mathrm{IC}_{50}$ and $\mathrm{IC}_{85}$ points for bicuculline displacing muscimol (Huang and Johnston, 1990). In most cases, bicuculline was found to antagonize the muscimol response at between 1 and $5 \mathrm{nA}$ ejecting current $(600 \mathrm{sec}=10 \mathrm{~min})$. 


\section{Table 1. Distribution of cells}

\begin{tabular}{llcc}
\hline Condition & Barrel & Septal & Total \\
\hline Control, urethane & 17 & 4 & 21 \\
Control, barbiturate & 18 & 17 & 35 \\
Muscimol + BMC, urethane & 27 & 7 & 34 \\
Muscimol + BMC, barbiturate & 14 & 4 & 18 \\
Total & 76 & 32 & 108
\end{tabular}

The numbers of cells located in septal and barrel locations are shown for control conditions and for cases in which the cortex was blocked with muscimol and subsequently locally disinhibited with BMC. The numbers of cells in different locations are broken down into those recorded under urethane and those under barbiturate anesthesia.

tively low in this study (Table 1), so our estimate of the proportion of septal cells retaining input in the absence of cortical activity is only a first approximation. However, similar behavior was seen under barbiturate anesthesia (see below), which suggests that the properties of the cells we recorded may be representative of many septal cells.

The second strongest whisker response was $65 \%$ of the most powerful whisker response in control cases and 25\% after treatment (note that a principal whisker is difficult to attribute in some of these cases). This value is significantly lower than that of the control, indicating some intracortical component to the surround receptive fields of these septal cells $(t=2.17 ; p<0.05 ; \mathrm{df}=$ 9 ), but greater than zero, indicating some thalamic component.

In contrast to the effect on the barrel cells, the application of $\mathrm{BMC}$ in muscimol-blocked cortex tended to increase the average response to both the principal and the $2^{\prime}$ surround whiskers. The principal whisker response increased 333\% (from 108 to 360 $\mathrm{sp} / 50 \mathrm{st}$ ), and the $2^{\prime}$ surround response increased by $139 \%$ (from 67.4 to $94 \mathrm{sp} / 50 \mathrm{st}$ ). Occasionally, the temporal response to the principal and surround whiskers was quicker in onset and briefer in duration after application of BMC compared with before muscimol application (see Fig. $6 \mathrm{~B}$ ). This is presumably because only the thalamic component of the response is available to drive the cell in this case, which it does in an exaggerated manner because of the BMC, whereas the longer-latency intracortical components are absent, making the response shorter in duration.

\section{Neurons located in the ventroposterior medial thalamic nucleus}

To check whether blocking intracortical activity affected the receptive field properties of thalamic neurons, one electrode was placed in the ventroposterior medial thalamic nucleus (VPm), and a second was placed in the corresponding receptive field area in the barrel cortex. Thalamic receptive fields were measured before and after application of muscimol to the cortex (Fig. 8). The cortical electrode was used to monitor the cortical activity blockade during thalamic recordings. Blocking intracortical transmission had no effect on VPm receptive field properties. The principal whisker responses were the same before and after muscimol application, as were the surround receptive field responses (principal whisker response: before cortical muscimol, 60.5 \pm 6.0 $\mathrm{sp} / 50 \mathrm{st}$; after cortical muscimol, $74.7 \pm 6.1 \mathrm{sp} / 50 \mathrm{st}$; secondary whisker response: before, $14.5 \pm 3.6 \mathrm{sp} / 50 \mathrm{st}$; after, $20.4 \pm 5.8$ $\mathrm{sp} / 50 \mathrm{st}$ ), and these values are not statistically different $(p>0.05$, $t$ test). Figure 8 shows that the kurtosis of the surround receptive field profile is not changed, either. The main surround receptive field whisker response is $24 \%$ of the principal whisker response before cortical muscimol application and $27 \%$ after. These results demonstrate that the thalamic input to the cortex was probably constant during application of muscimol to the cortex.

\section{Effect of anesthetic on cortical receptive fields in the absence of intracortical activity}

Although it is unlikely that the organization of receptive fields described above can be ascribed to the anesthetic, we wanted to check whether the same results were evident when using an anesthetic with a different mode of action. Therefore, we repeated the experiment in animals anesthetized with sodium pentobarbitone. This anesthetic principally affects GABAergic receptors (Dilger, 2002) and therefore gives the advantage that our manipulations with the anesthetic, muscimol, and BMC were affecting the same main target. The level of anesthesia was maintained constant for each animal (see Materials and Methods). Therefore, once the muscimol had diffused into the cortex the only variable involved was BMC.

In barrel neurons, as found with urethane anesthesia, the average response of the principal whisker under muscimol blockade could be increased greatly above control levels without, in most cases, revealing any surround receptive field component (Fig. 9). On average, the principal whisker response reactivated by BMC was $230 \%$ greater than the average control response (test mean, $100.6 \mathrm{sp} / 50 \mathrm{st} ; n=14$; control, $43.75 \mathrm{sp} / 50 \mathrm{st} ; n=18$ ). The surround receptive fields when present were limited to at most one other whisker. In muscimol-treated cortex, neurons "responded" to stimulation of the $2^{\prime}-5^{\prime}$ whiskers at $7,0,0$, and $0 \%$ of the principal whisker response, respectively. In contrast, neurons in untreated cortex responded to surround whisker stimulation of the $2^{\prime}-5^{\prime}$ whiskers at $18.5,12.3,11.8$, and $10 \%$ of the principal whisker response, respectively. The $3^{\prime}-5^{\prime}$ surround receptive field values for muscimol-treated cortex are all significantly different from control (Fig. 9).

In septal neurons, consistent with the result in urethaneanesthetized animals, the effect of blocking intracortical transmission in pentobarbitone-anesthetized animals was less pronounced than for barrel cells. Neurons retained responses from a surround receptive field whisker when treated locally with BMC (Fig. 9). The second strongest whisker response was $46.7 \%$ of the most powerful whisker response in control cases $(n=17)$ and $44 \%$ after muscimol and local BMC treatment $(n=4)$. Similarly, the $3^{\prime}-5^{\prime}$ whiskers generated smaller but significant responses of 8,5 , and $3 \%$ of the principal whisker response, respectively, in locally activated cortex compared with 32,25 , and 15\%, respectively, in untreated cortex. The sample of septal cells in barbiturate-anesthetized animals was too low to achieve significance with statistical tests (Table 1) but showed a tendency similar to those recorded under urethane anesthesia.

\section{Discussion}

We found that when intracortical activity is limited to the immediate surrounds of the layer IV barrel neuron the receptive field shrinks to a single whisker with occasional evidence of a weak second whisker input. In contrast, septal cells often showed multiwhisker responses in the absence of intracortical transmission. These findings were consistent independent of whether the experiments were conducted in urethane- or barbiturateanesthetized animals. Neither could these findings be explained by a reduction in thalamic receptive field size attributable to treatment of the cortex with muscimol because thalamic receptive fields remained constant in the thalamus during this procedure. The most likely explanation for these findings is that the surround receptive fields of barrel neurons are generated intracortically. This view is consistent with experiments in which we blocked activity in a single barrel. Inactivating a single barrel with muscimol selectively removed the corresponding whisker from 
A Barrel Control

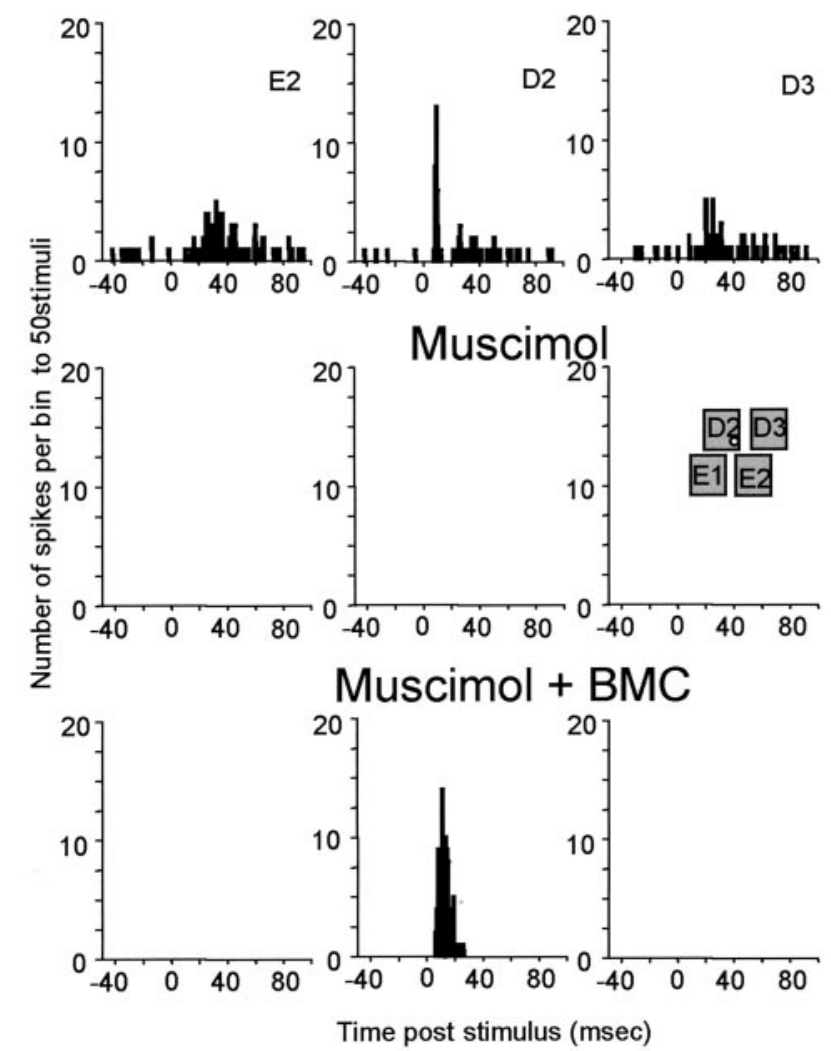

\section{B Septum Control}
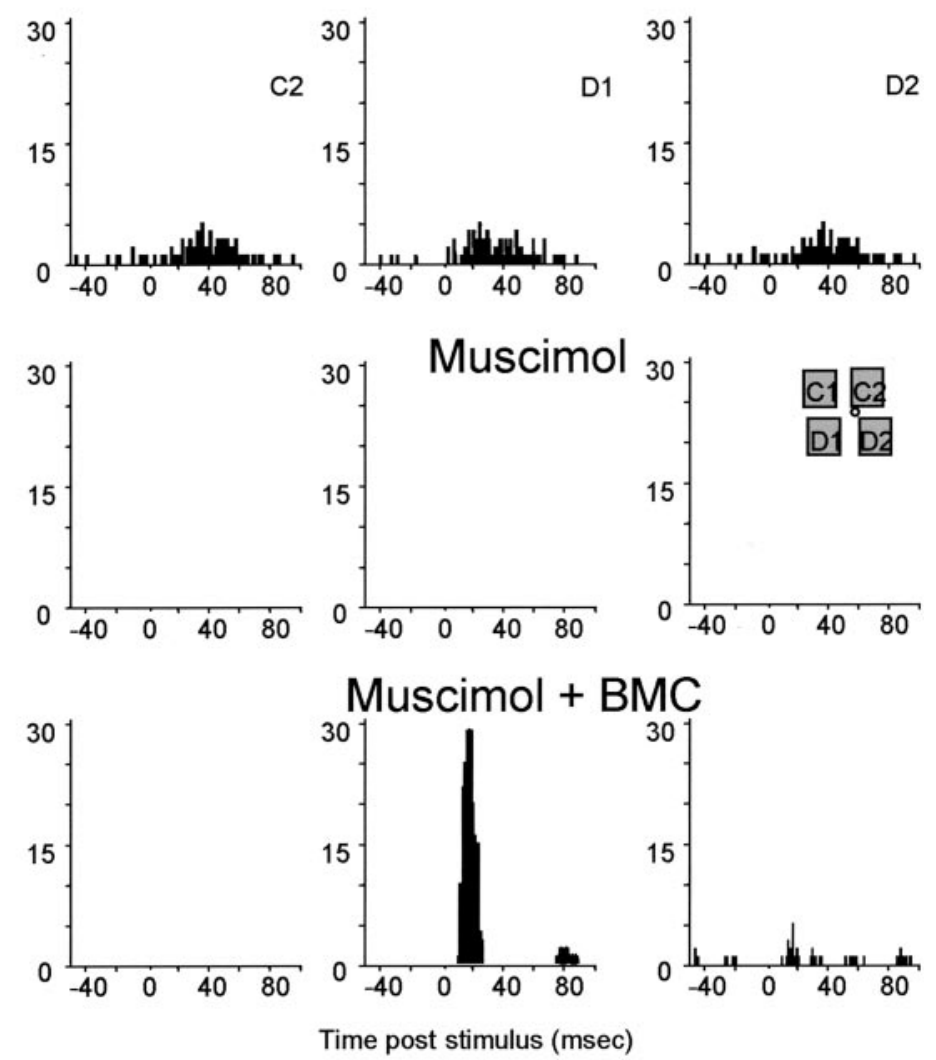

Figure 6. Examples of local reactivation during muscimol block for cells located in a barrel or in a septum. A, Barrel, Poststimulus time histograms are shown for responses to principal whisker stimulation (D2) and two of the surround receptive field whiskers (E2 and D3) for a cell located in the D2 barrel (inset). Top panels, Control responses. All activity is lost when muscimol is subsequently diffused from the surface of the cortex (middle traces). Bottom panels, Iontophoresis of BMC reveals an input to the cell from the principal whisker but no response from surround receptive field whiskers. B, Septum, Similar results are found for cells located in the septum, except that surround receptive field components are also revealed occasionally. This cell was located in the septum between $\mathrm{C} 2$ and D2. It initially responds evenly to the C2, D1, and D2 whiskers. After iontophoresis of bicuculline during cortical blockade with muscimol, the D1 whisker evokes a far greater response in the cell than in the control case (bottom panels). The D2 whisker also produces a small response.

the surround receptive field of a neuron located in the neighboring barrel.

\section{Receptive field size measurements}

Previous measurements of receptive field size have shown that as many as 15 whiskers can generate suprathreshold extracellular responses in cortical cells, and, on average, approximately eight whiskers can produce an output in a particular neuron (Armstrong-James and Fox, 1987). Similar findings have been reported after intracellular recordings in which 7-16 whiskers have been shown to generate EPSPs, the majority of which were subthreshold for spiking under the anesthetic conditions used (Moore and Nelson, 1998; Zhu and Connors, 1999). The degree to which the inputs are translated into outputs depends partly on general levels of excitability, which under experimental conditions depend on the level of anesthesia. In our studies, it was possible to look at subthreshold responses by using bicuculline to disinhibit neurons.

For barrel neurons, we found that local disinhibition produced a large increase in the surround receptive field response provided that intracortical transmission was intact, but that disinhibition did not reveal any surround receptive field response when intracortical activity was blocked. Some exposure of the surround receptive field input would be expected if it had been present because (1) the surround receptive field was suprathreshold under the conditions in which we recorded before blocking intracortical transmission; (2) the surround receptive field is sensitive to treatment by bicuculline; (3) the principal whisker response was easily brought from subthreshold to generate double its normal level of response by local disinhibition; and (4) the surround receptive fields were easily brought above threshold by the same means in septal cells. This implies that the suprathreshold and subthreshold multivibrissae receptive field components reported in previous studies originate in the cortex.

Receptive field size is known to be affected by anesthetic level (Armstrong-James and George, 1988; Friedberg et al., 1999); therefore, it was carefully monitored and controlled at levels equivalent to those used in other studies (see Materials and Methods). It has been suggested that receptive fields might differ under urethane anesthesia (Simons et al., 1992); therefore, we repeated the experiments under barbiturate anesthesia. Mechanistically, urethane anesthesia decreases NMDA and non-NMDA receptor function approximately equally and enhances GABAergic receptor function (Hara and Harris, 2002), whereas barbiturates appear to have a simpler action, acting principally as a $\mathrm{GABA}_{\mathrm{A}}$ agonist (Steinbach and Akk, 2001). In practice, the findings were similar under urethane and barbiturate anesthesia in that surround receptive fields were present when intracortical transmis- 


\section{A Principal and Surround receptive field responses}

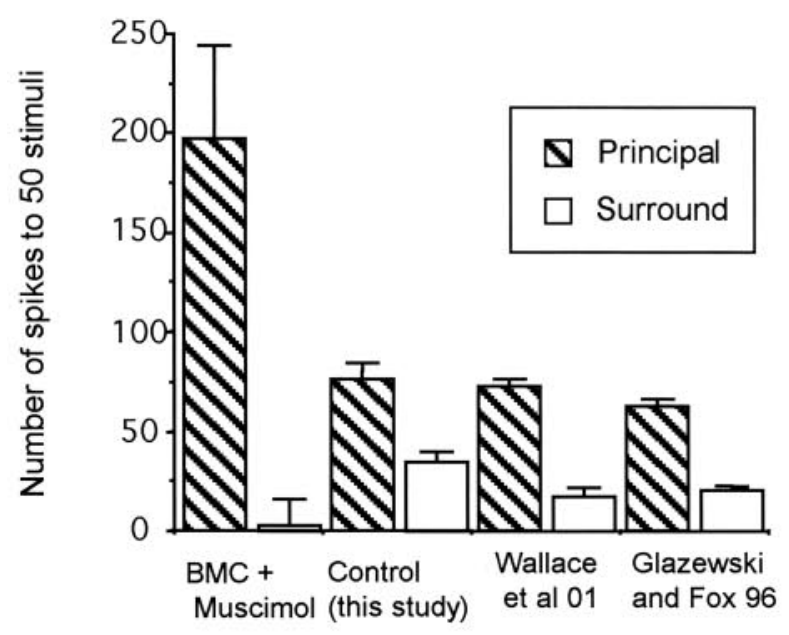

\section{B Effect of BMC on globally inhibited cortex}

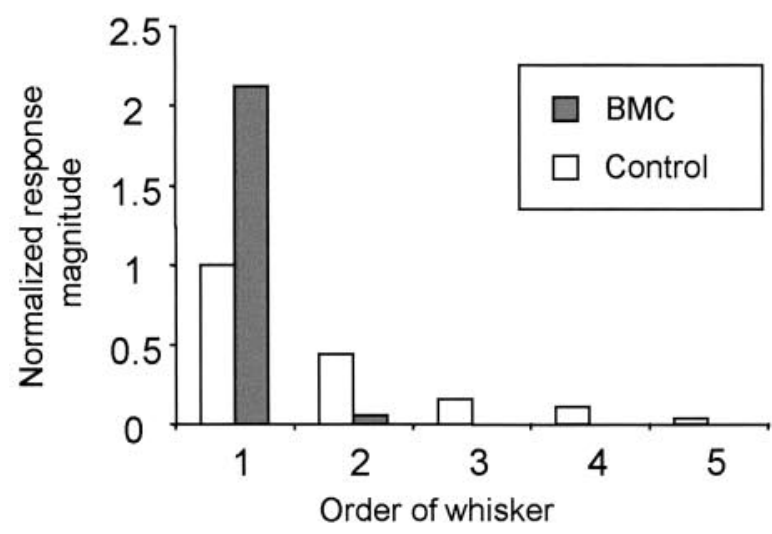

C

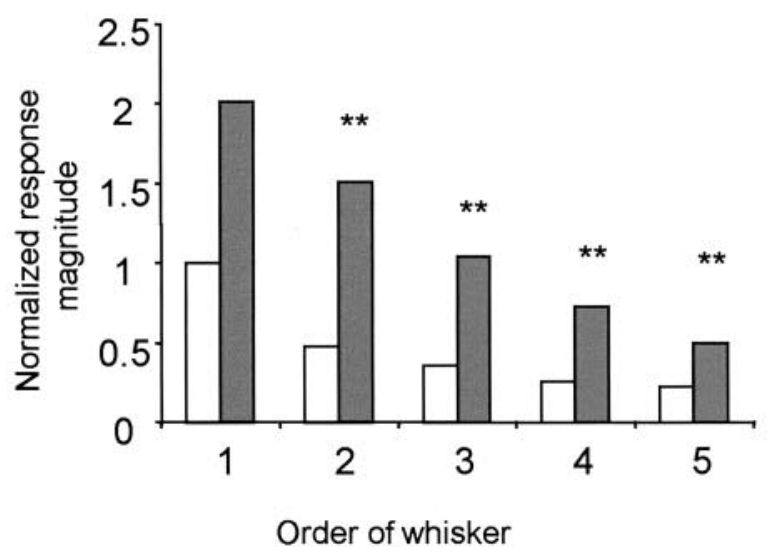

Figure 7. Quantification of sensory responses during local reactivation of barrel locations. $A$, Average responses are shown for stimulation of the principal whisker (hatched bars) and the surround receptive field whisker (white bars) for barrel cells. Control principal whisker responses are very similar across three studies (Glazewski and Fox, 1996; Wallace et al., 2001; this study). The control surround whisker responses are slightly higher in this study than in those in sion was intact but absent when it was blocked. Other studies have also found receptive fields to be similar under urethane and barbiturate anesthesia (cf. Moore and Nelson, 1998; Zhu and Connors, 1999). In our hands, the response levels were lower in barbiturate anesthesia but nevertheless showed just as many multiwhisker receptive fields at an equivalent anesthetic level provided intracortical transmission was present. In any case, because barbiturate acts principally on GABA receptors, any differences in anesthetic level should have been reversed locally by bicuculline.

\section{Intracortical transmission}

In these studies, we created conditions in which the local neuronal circuit in the barrel was strongly disinhibited by bicuculline, yet under these conditions, practically all the barrel neurons showed single whisker receptive fields in the absence of intracortical transmission. The principal whisker response could be elevated from zero to twice its control value with bicuculline without revealing a surround receptive field component in almost all cases. Because the thalamic afferents are unaffected by manipulation of the postsynaptic GABAergic receptors and are not restricted by inhibition from depolarizing the postsynaptic cells, this implies that they cannot be responsible for generating layer IV surround receptive fields. This leaves the possibility that the surround receptive fields of layer IV barrel neurons are generated intracortically; in which case, from what source?

Recent studies performed on living slices of barrel cortex imaged using voltage-sensitive dyes have shown that there is no spread of excitation between columns at the level of layer IV when the thalamic inputs are stimulated electrically (Petersen and Sakmann, 2001; Laaris and Keller, 2002). Similarly, studies using natural stimuli have indicated that single barrel lesions do not affect surround receptive fields in layer IV, although they do abolish the representation of the corresponding whisker in layers II and III (Goldreich et al., 1999).

Nevertheless, there are at least two pathways by which excitation could be transferred between barrel columns. Anatomical tracer experiments show that horizontal connections link barrels at the supragranular and infragranular levels (Bernardo et al., 1990). One possibility is that these connect with the layer IV pyramidal and star pyramidal cells located in the barrels and receive neighboring whisker information from the neighboring barrel column. A second possibility is that the relevant connections run directly between the barrels. Although there are fewer and shorter-range direct transbarrel connections in layer IV than in superficial or infragranular layers, they nevertheless exist (Bernardo et al., 1990). Furthermore, recent slice studies using release

\footnotetext{
previous studies, which probably reflects the bias to study only cells with surround receptive fields here. The principal whisker response is more than twice as great during BMC reactivation than it is for control conditions. However, disinhibition does not reactivate surround whisker responses, which remain a small fraction of their control values and a tinier fraction of the principal whisker response. $B$, The effect of BMC is shown for cases in which the cortex is globally blocked with muscimol treatment (gray bars) compared with the control unblocked condition (white bars). The responses are normalized to the principal whisker responses in control cases. Note that although BMC doubles the principal whisker response in the absence of intracortical activity, other receptive field components are either absent or marginal. The $x$-axis categorizes the order of the whisker, i.e., from principal whisker $\left(1^{\prime}\right)$ to the fifth most efficacious whisker $\left(5^{\prime}\right) . C$, BMC has a profound effect on all components of the receptive field in animals in which intracortical transmission is intact; again, it doubles the principal whisker response but generally triples the surround receptive field components. ${ }^{*}$ Significance at $p<0.01$, referring to the difference between the effect of BMC in normal and muscimol-treated cortex.
} 


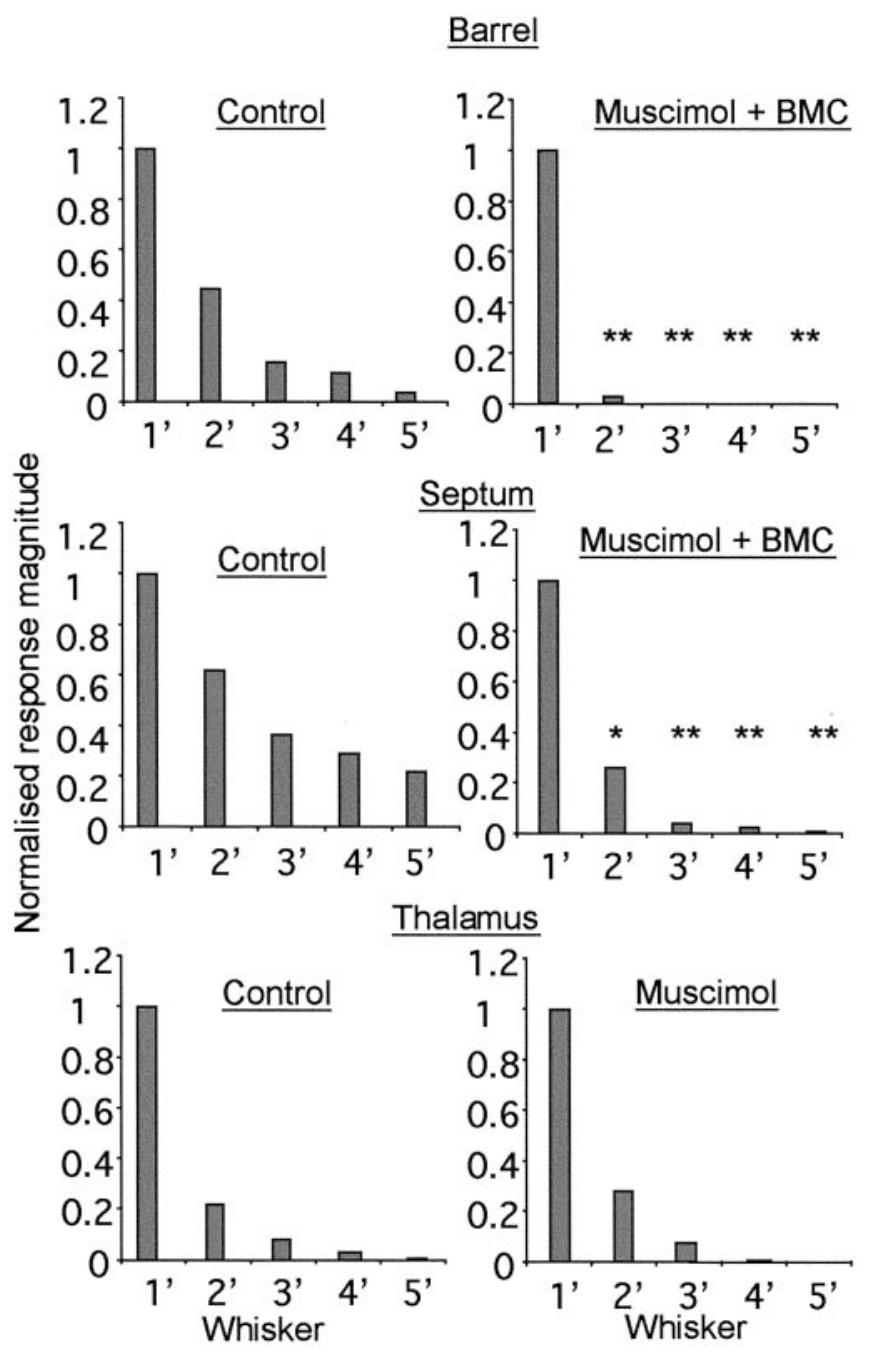

Figure 8. Comparison of barrel, septal, and thalamic receptive fields in the presence or absence of intracortical transmission. Normalized responses to principal $\left(1^{\prime}\right)$ and surround receptive field $\left(2^{\prime}-5^{\prime}\right)$ whiskers are shown for cells located in barrels (top), for septal cells (middle), and for thalamic VPm cells (bottom). The whisker responses are ordered from most effective in inducing a response to least effective for five whiskers in the receptive field. Control responses (left column) are compared with responses measured during blockade of cortical activity with muscimol (right column). In the case of the cortical cells this involves local reactivation with BMC. Barrel, In the locally reactivated cortex (muscimol + BMC), note the general lack of response to stimulation of surround receptive field whiskers except for a weak response from one other whisker. Surround receptive field responses are different from control, but the principal whisker response is not. *Significance at $p<0.05$; ${ }^{* *} p<0.01$. Septum, Although surround receptive fields are significantly reduced by the treatment, far more of the surround receptive field survives the treatment than is the case for the barrel cells. Thalamus, There is no change in the surround receptive field profile during cortical muscimol treatment, and there are no significant differences for surround receptive fields comparing cortical muscimol treatment with control.

of caged glutamate do show evidence of transbarrel communication (Schubert et al., 2003). These studies show that transbarrel pathways project primarily to pyramidal cells in layer IV, whereas spiny stellate neurons primarily process intrabarrel information (Schubert et al., 2003). In addition, transbarrel projections evoke EPSPs and IPSPs in cells located in neighboring barrels.

The lack of evidence for transbarrel communication in some slice studies may therefore be attributable to the difficulty in cutting the slice to preserve all the required connections. Therefore, it is possible that layer IV surround receptive fields are derived directly from neighboring barrels. The lack of evidence for trans-

\section{Pentobarbitone}

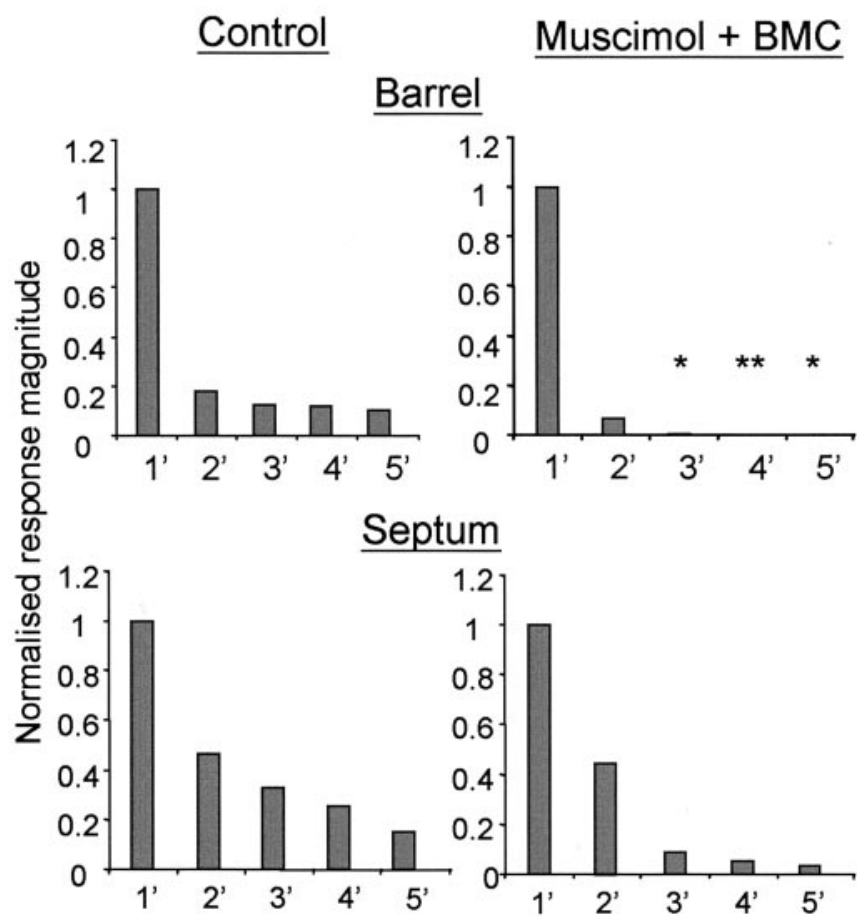

Figure 9. Sensory responses during local reactivation of barrel and septal cells in animals anesthetized with pentobarbitone. Normalized receptive fields are shown for barrel (top row) and septal neurons (bottom row). Top, Blocking cortical activity with muscimol and locally reactivating with $\mathrm{BMC}$ reveals a single whisker receptive field and a minor secondary whisker component in cells located in barrels. The principal and secondary whiskers are not different from the control, whereas the other surround receptive field components are. *Significance at $p<0.05$; ${ }^{* *} p<0.01$. Bottom, The effect is less pronounced in the case of septal cells, in which local reactivation reinstates most of the surround receptive field. The surround receptive fields are not significantly different from that of the control.

barrel communication in some in vivo experiments may be because it is often difficult to ablate a barrel completely in these studies (Goldreich et al., 1999). Even small surviving fragments of the ablated barrel are sufficient to support surround receptive field inputs to neighboring barrels (Fox, 1994), and these are not discovered until after the recording has finished. An advantage of the iontophoretic "lesion" reported here is that it allows the degree of the block to be varied and increased during the experiment if necessary. The present results show that a "reversible lesion" created by iontophoresis of muscimol can selectively abolish responses to the whisker related to the inhibited barrel.

\section{Differences between barrel and septal subdivisions}

A distinction was found between the behavior of septal and barrel cells to abolition of intracortical activity. Although barrel cells tended to lose their surround receptive fields, septal receptive fields decreased in size and intensity but were not completely abolished. This suggests that unlike barrel cells, septal cells do derive some surround receptive field input from the thalamus. One explanation for this finding is based on the fact that septal and barrel innervations arise from thalamic neurons with different receptive field properties. It has been shown that the somatosensory part of the posterior thalamic nucleus ( $\mathrm{POm}$ ) projects to the septal region (Koralek et al., 1988), but it is unlikely to have influenced septal receptive fields in these studies because POm relies on cortical activity itself for full expression of its receptive 
fields (Diamond et al., 1992). Because we had inhibited cortex with muscimol, one would expect POm to be silenced, too. A more likely explanation is that the subset of thalamic cells in the tail portion of the barreloids (VPMvl), which project to the septal regions of the barrel field (as well as S2), are responsible for the multiwhisker responses of the septal cells in the absence of intracortical activity (Pierret et al., 2000). The VPMvl neurons receive input from the interpolaris nucleus of the brainstem trigeminal nuclei, which itself exhibits multiwhisker receptive fields, and might therefore project this information via VPMvl to the cortex (Woolston et al., 1982; Jacquin et al., 1989; Pierret et al., 2000).

\section{Implications for information processing}

The present results imply that information from a single whisker is relayed within the cortex to the adjacent columns either from the principal barrel or to some extent from mixed whisker information in septal regions. Despite transmission through several synapses, the unmixed information from individual whiskers arrives in the cortex intact. This arrangement gives greater flexibility for the way individual whisker information is combined or integrated by the cortical circuitry than if it had arrived premixed. It therefore seems likely that the cortical surround receptive field structure is synthesized by the connectivity of intracortical connections. For example, layer II and III cells receive a strong projection from layer IV cells in their principal barrel, thereby providing their principal whisker input; on the other hand, connections from neighboring barrels provide their surround receptive field information. Future studies will be required to track the information flow from individual barrels to see how receptive fields are generated in different layers of the cortex. Finally, it has been noted that subcortical structures in the somatosensory system show little if any experience-dependent plasticity, whereas cortical pathways show plasticity into adulthood (Fox et al., 2002). Therefore, one of the advantages of generating surround receptive field information in the cortex rather than subcortically is that it allows the system to remain more adaptable to changes in the periphery throughout life.

\section{References}

Armstrong-James M, Fox K (1987) Spatiotemporal convergence and divergence in the rat S1 "barrel" cortex. J Comp Neurol 263:265-281.

Armstrong-James M, George MJ (1988) Influence of anesthesia on spontaneous activity and receptive field size of single units in rat $\mathrm{SmI}$ neocortex. Exp Neurol 99:369-387.

Armstrong-James M, Fox K, Kruk ZL, Millar J (1982) Quantitative iontophoresis of catecholamines using multibarrel carbon fibre microelectrodes. J Neurosci Methods 4:385-407.

Armstrong-James M, Fox K, Das-Gupta A (1992) Flow of excitation within rat barrel cortex on striking a single vibrissa. J Neurophysiol 68:1345-1358.

Bernardo KL, McCasland JS, Woolsey TA (1990) Local axonal trajectories in mouse barrel cortex. Exp Brain Res 82:247-253.

Buonomano DV, Merzenich MM (1998) Cortical plasticity: from synapses to maps. Annu Rev Neurosci 21:149-186.

Carslaw HS, Jaeger JC (1956) The conduction of heat in solids. London: Oxford UP.

Diamond ME, Armstrong-James M, Budway MJ, Ebner FF (1992) Somatic sensory responses in the rostral sector of the posterior group (POm) and in the ventral posterior medial nucleus (VPM) of the rat thalamus: dependence on the barrel field cortex. J Comp Neurol 319:66-84.

Dilger JP (2002) The effects of anesthetics on ligand-gated ion channels. Br J Anaesth 89:41-51.

Fox K (1994) The cortical component of experience-dependent synaptic plasticity in the rat barrel cortex. J Neurosci 14:7665-7679.

Fox K, Armstrong-James M (1986) The role of the anterior intralaminar nuclei and $N$-methyl D-aspartate receptors in the generation of spontaneous bursts in rat neocortical neurones. Exp Brain Res 63:505-518.

Fox K, Schlaggar BL, Glazewski S, O’Leary DD (1996) Glutamate receptor blockade at cortical synapses disrupts development of thalamocortical and columnar organization in somatosensory cortex. Proc Natl Acad Sci USA 93:5584-5589.

Fox K, Glazewski S, Wallace H (2002) Is there a thalamic component to experience-dependent cortical plasticity? Philos Trans R Soc Lond B Biol Sci 357:1709-1715.

Friedberg MH, Lee SM, Ebner FF (1999) Modulation of receptive field properties of thalamic somatosensory neurons by the depth of anesthesia. J Neurophysiol 81:2243-2252.

Fujita I, Tanaka K, Ito M, Cheng K (1992) Columns for visual features of objects in monkey inferotemporal cortex. Nature 360:343-346.

Glazewski S, Fox K (1996) Time course of experience-dependent synaptic potentiation and depression in barrel cortex of adolescent rats. J Neurophysiol 75:1714-1729.

Goldreich D, Kyriazi HT, Simons DJ (1999) Functional independence of layer IV barrels in rodent somatosensory cortex. J Neurophysiol 82:1311-1316.

Guedal AE (1920) Signs of inhalation anesthesia: a fundamental guide. In: Inhalation anesthesia (Guedal AE, ed), pp 10-52. New York: Macmillian.

Hara K, Harris RA (2002) The anesthetic mechanism of urethane: the effects on neurotransmitter-gated ion channels. Anesth Analg 94:313-318.

Huang JH, Johnston GA (1990) (+)-Hydrastine, a potent competitive antagonist at mammalian GABAA receptors. Br J Pharmacol 99:727-730.

Hubel DH, Wiesel TN (1962) Receptive fields, binocular interaction and functional architecture in the cat's visual cortex. J Physiol 160:106-154.

Jacquin MF, Barcia M, Rhoades RW (1989) Structure-function relationships in rat brainstem subnucleus interpolaris: IV. Projection neurons. J Comp Neurol 282:45-62.

Koralek KA, Jensen KF, Killackey HP (1988) Evidence for two complementary patterns of thalamic input to the rat somatosensory cortex. Brain Res 463:346-351.

Laaris N, Keller A (2002) Functional independence of layer IV barrels. J Neurophysiol 87:1028-1034.

Lubke J, Egger V, Sakmann B, Feldmeyer D (2000) Columnar organization of dendrites and axons of single and synaptically coupled excitatory spiny neurons in layer 4 of the rat barrel cortex. J Neurosci 20:5300-5311.

Mountcastle VB (1957) Modality and topographic properties of single neurons of cat's somatic sensory cortex. J Neurophysiol 20:408-434.

Moore CI, Nelson SB (1998) Spatio-temporal subthreshold receptive fields in the vibrissa representation of rat primary somatosensory cortex. J Neurophysiol 80:2882-2892.

Nicholson C, Phillips JM (1981) Ion diffusion modified by tortuosity and volume fraction in the extracellular microenvironment of the rat cerebellum. J Physiol (Lond) 321:225-257.

Petersen RS, Diamond ME (2000) Spatiotemporal distribution of whisker evoked activity in rat somatosensory cortex and the coding of stimulus location. J Neurosci 20:6135-6143.

Petersen CC, Sakmann B (2001) Functionally independent columns of rat somatosensory barrel cortex revealed with voltage-sensitive dye imaging. J Neurosci 21:8435-8446.

Pierret T, Lavallee P, Deschenes M (2000) Parallel streams for the relay of vibrissal information through thalamic barreloids. J Neurosci 20:7455-7462.

Schubert D, Kotter R, Zilles K, Luhmann HJ, Staiger JF (2003) Cell-type specific circuitry of layer IV spiny neurons. J Neurosci 23:2961-2970.

Simons DJ (1985) Temporal and spatial integration in the rat SI vibrissa cortex. J Neurophysiol 54:615-635.

Simons DJ, Woolsey TA (1984) Morphology of Golgi-Cox-impregnated barrel neurons in rat SmI cortex. J Comp Neurol 230:119-132.

Simons DJ, Carvell GE, Hershey AE, Bryant DP (1992) Responses of barrel cortex neurons in awake rats and effects of urethane anesthesia. Exp Brain Res 91:259-272.

Steinbach JH, Akk G (2001) Modulation of GABA(A) receptor channel gating by pentobarbital. J Physiol (Lond) 537:715-733.

Szentagothai J (1975) The "module-concept" in cerebral cortex architecture. Brain Res 95:475-496.

Tsunoda K, Yamane Y, Nishizaki M, Tanifuji M (2001) Complex objects are 
represented in macaque inferotemporal cortex by the combination of feature columns. Nat Neurosci 4:832-838.

Wallace H, Glazewski S, Liming K, Fox K (2001) The role of cortical activity in experience-dependent potentiation and depression of sensory responses in rat barrel cortex. J Neurosci 21:3881-3894.

Wong-Riley M (1979) Changes in the visual system of monocularly sutured or enucleated cats demonstrable with cytochrome oxidase histochemistry. Brain Res 171:11-28.

Woolsey TA, Van der Loos H (1970) The structural organization of layer IV in the somatosensory region (SI) of mouse cerebral cortex. The description of a cortical field composed of discrete cytoarchitectonic units. Brain Res 17:205-242.

Woolston DC, La Londe JR, Gibson JM (1982) Comparison of response properties of cerebellar- and thalamic-projecting interpolaris neurons. J Neurophysiol 48:160-173.

Zhu JJ, Connors BW (1999) Intrinsic firing patterns and whisker-evoked synaptic responses of neurons in the rat barrel cortex. J Neurophysiol 81:1171-1183. 